Eixo Temático: Processos de Ensino-Aprendizagem

\title{
ET-06-008 \\ CONCEPÇÕES ALTERNATIVAS SOBRE O EFEITO ESTUFA: IMPLICAÇÕES PARA O ENSINO DE CIÊNCIAS NA EDUCAÇÃO BÁSICA
}

Elivelton Veríssimo de Souza, Maria San Miris Lopes de Oliveira, Cristiane Souza de Menezes

Centro de Educação. Universidade Federal de Pernambuco.

http://dx.doi.org/10.21472/congrebio2016.et-06-008

\section{RESUMO}

As concepções alternativas têm como base a formação de ideias a partir das convicções, concepções ou noções que os alunos formulam sobre determinado conceito ou fenômeno, antes ou durante o ensino e que diferem das concepções científicas. A partir delas o aluno tenta dar sentido aos fenômenos do seu cotidiano. Assim, esse trabalho tem como objetivo identificar as concepções alternativas de estudantes e professores da educação básica a respeito do fenômeno do efeito estufa. Para isso, foram realizadas seis entrevistas para saber as concepções dos participantes da pesquisa sobre o assunto. Em geral foi comum encontrar pessoas com diferentes opiniões e ideias, que entendem e relacionam o efeito estufa à camada de ozônio ou acham que os dois são a mesma coisa. O efeito estufa foi apresentado como algo ruim pelos alunos e professores, apesar de ser um evento natural que favorece a proliferação da vida no planeta. Além disso, o desconhecimento de algumas informações científicas por parte dos professores a respeito do fenômeno interfere nitidamente na qualidade do ensino de ciências.

Palavras-chave: Concepções alternativas; Ensino de Ciências; Efeito Estufa.

\section{INTRODUÇÃO}

A “concepção", tal como a reconhecemos, não é um produto, mas sim o processo de uma atividade de construção mental do real. Essa elaboração efetua-se, é claro, a partir das informações que o aprendente recebe por meio de seus sentidos, mas também das relações que mantém com outros indivíduos ou grupos, durante sua história, e que permanecem gravadas em sua memória. Mas essas informações são codificadas, organizadas, categorizadas num sistema cognitivo global e coerente, em relação com suas preocupações e os usos que lhes dá (GIORDAN, 1996).

Dessa forma, no processo do conhecimento participam os sentidos, a razão e a intuição. É muito provável que a sabedoria humana não resolva realmente todos os problemas de modo sistemático. Mas depois que o problema é resolvido, o método científico é utilizado para explicá-lo e expor a sua solução de um modo ordenado para poder ser compreendido por todos aqueles que estão no processo da produção científica, e precisam compreender que a ciência possui um plano formal de desenvolvimento.

Essa noção permite entender a evolução das ideias dos estudantes em sala de aula não como uma substituição de ideias alternativas por ideias científicas, mas como a evolução de um perfil de concepções, em que as novas ideias adquiridas no processo de ensino-aprendizagem passam a conviver com as ideias anteriores, sendo que cada uma delas pode ser empregada no contexto conveniente (MORTIMER, 1996). Dessa forma, o método nos leva a: Apresentar o tema; enunciar o problema; rever a bibliografia existente; formular hipóteses e variáveis; interpretar as informações; tirar dúvidas. 
As concepções denominadas prévias, alternativas ou espontâneas são semelhantes para pessoas de diferentes faixas etária, ambientes culturais e estão organizadas com grau suficiente de coerência interna, o que as toma muito resistente às mudanças (SILVA, 2009).

\section{OBJETIVO}

Nosso objetivo é identificar as concepções alternativas de estudantes e professores da educação básica a respeito do fenômeno do efeito estufa.

\section{METODOLOGIA}

A pesquisa foi realizada como pré-requisito de avaliação da disciplina Metodologia do Ensino de Biologia 1, aplicada no $1^{\circ}$ período do curso de licenciatura em Ciências Biológicas da Universidade Federal de Pernambuco. Foram entrevistados 3 alunos do $9^{\circ}$ ano de uma escola da rede municipal do Recife; 1 aluno do ensino médio de uma escola da rede estadual de Pernambuco e 2 professores das disciplinas de Ciências e Geografia também de uma escola da rede estadual de Pernambuco.

As perguntas feitas aos entrevistados foram de acordo com seu grau de escolaridade e idade, e a entrevista foi realizada de modo claro, objetivo e de fácil entendimento dos questionados e com a duração média de 5 minutos com cada entrevistado. As questões abordadas foram:

1. O que é efeito estufa? (alunos do Ensino fundamental, Ensino médio e Professores).

2. Faça um desenho que represente o efeito estufa. (alunos do Ensino fundamental)

3. Quais as consequências do efeito estufa? (alunos do Ensino fundamental, Ensino médio e Professores). Professores).

4. Quais as causa do efeito estufa? (alunos do Ensino fundamental, Ensino médio e Professores).

5. Como evitar o efeito estufa? (alunos do Ensino fundamental, Ensino médio e

6. Qual sua metodologia para trabalhar efeito estufa na sala de aula? (Professores).

\section{RESULTADOS E DISCUSSÃO}

As seguintes respostas foram dadas pelos alunos de ensino fundamental:

\section{O que é o efeito estufa?}

G.G. - 13 anos, $9^{\circ}$ ano - "O efeito estufa é um mecanismo natural da terra para equilibrar a temperatura."

M.E. B- 15 anos, $9^{\circ}$ ano - "O efeito estufa é o processo de aquecimento do planeta, onde os raios do sol são absorvidos por gases liberados na terra, provocando o efeito estufa, logo o aquecimento global."

M.E. S - 15 anos, $9^{\circ}$ ano - "O efeito estufa é um processo que ocorre quando uma parte da radiação solar é emitida na superfície da terra e absorvida por determinados gases presentes na atmosfera.” 


\section{Faça um desenho que represente o efeito estufa.}

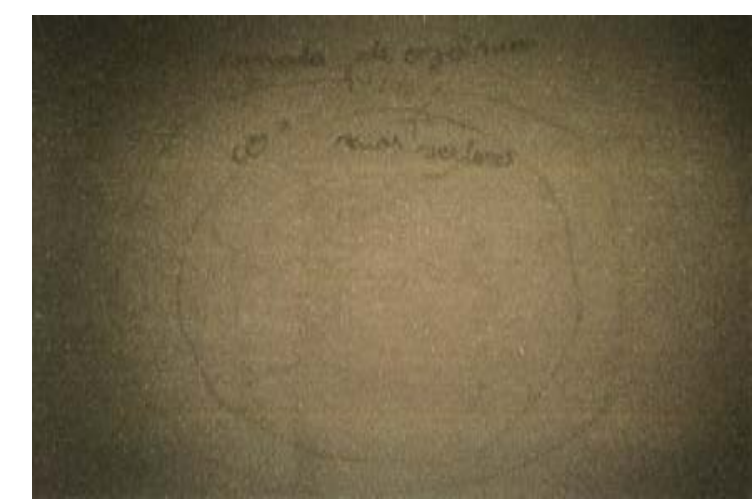

G.G. -13 anos $/ 9^{\circ}$ ano

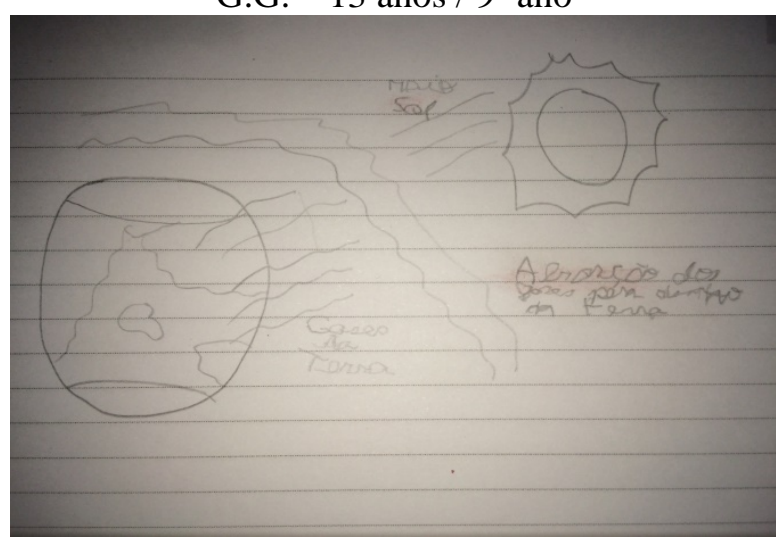

M.E.B. -15 anos $/ 9^{\circ}$ ano

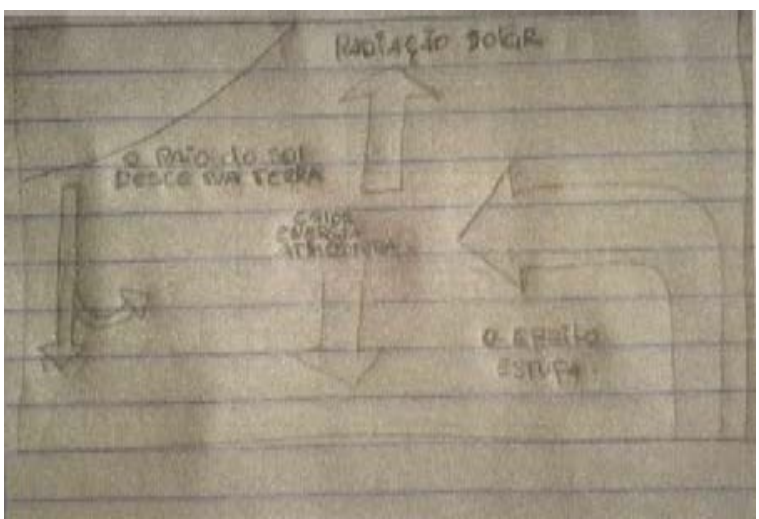

M.E.S. -15 anos $/ 9^{\circ}$ ano

As seguintes respostas foram dadas pelo aluno do ensino médio:

I.G - 16 anos, $1^{\circ}$ ano ensino médio.

1. $O$ que $o$ efeito estufa?

-“É quando o planeta esquenta a terra e altera o clima da terra.”

3. Quais as consequências do efeito estufa?

-"Secas, inundações porquê as geleiras derretem, variação na temperatura."

\section{O que causa o efeito estufa?}

-"Poluição e desmatamento." 


\section{Como evitar o efeito estufa?}

-"Preservando o meio ambiente."

As seguintes respostas foram dadas pelos professores:

S.L. - 36 anos, Professora de Geografia.

1. O que é o efeito estufa?

-“Corresponde ao aquecimento natural do planeta terra. Tal mecanismo é essencial para o desenvolvimento, manutenção e equilíbrio da vida na terra.”

2. Qual a sua metodologia para trabalhar efeito estufa na sala de aula?

-“Análise e interpretação de textos; Análise de imagens; Vídeos e discussão em sala; Artigos de jornais e revistas.”

\section{Quais as consequências do efeito estufa?}

- "O efeito estufa causa excesso de gases na atmosfera, em especial o carbônico, que fica retido e com isso gerando descontrole climático, como exemplo as altas temperaturas.”

\section{4. $O$ que causa o efeito estufa?}

-“Poluição, excesso na liberação de gases (principalmente $\mathrm{CO}_{2)}$, desflorestamentoilegal.”

\section{Como evitar o efeito estufa?}

-“ Preservando a natureza pra ser mais sucinto.”

D.C. - 29 anos- Professora de Ciências.

1. O que é o efeito estufa?

-"Sobrecarga de raios solares, que ao invés de serem eliminados, eles ficam retidos na camada atmosférica, causando mais danos a nós e a natureza.”

\section{Qual a sua metodologia para trabalhar efeito estufa em sala de aula?}

-"Peço que eles (os alunos) imaginem uma panela com água fervendo com a tampa e sem a tampa, sem a tampa o calor se espalha pelo ar, não deixando tão quente aquela região e com a tampa, o calor fica retido, chegando a formar as gotículas de agua na tampa, sinal de que aquele vapor não tinha por onde sair, ficando naquela região e ao tocarmos na tampa, ela estará muito quente."

\section{Quais as consequências do efeito estufa?}

-"Desregularidade no nosso ecossistema, a fauna e a flora são as que mais sentem esse impacto. Com o aumento das temperaturas os animais não conseguem se adaptar a essa constante mudança e com isso vãofugindo de seus habitats naturais podendo até ser extintos.

\section{O que causa o efeito estufa?}

-“Em geral, a não preservação do ambiente. Desmatamento, liberação de gás carbônico na atmosfera, poluição nos rios e mares.”

\section{Como evitar o efeito estufa?}

-“Como as plantas respiram gás carbônico, que é um dos mais poluentes, sugiro plantar mais árvores nos grandes centros pra tentar equilibrar ou reverter essa situação, e também evitar a liberação desses gases já que são eles os principais causadores o efeito estufa.”

Os dados revelados nas entrevistas e nos desenhos nos permitem constatar que há déficit no conhecimento sobre o tema proposto. Os alunos, por exemplo, têm uma concepção negativa 
sobre o efeito estufa, não identificando que tal fenômeno também beneficia o planeta Terra. Esses resultados se aproximam dos encontrados em pesquisa realizada por Libanore (2009) com 40 alunos da $8^{\circ}$ série do ensino fundamental de uma escola particular de um município da região noroeste do Estado do Paraná.

\section{CONCLUSÃO}

Essa pesquisa constatou que tanto os alunos como os professores possuem ideias alternativas a respeito do fenômeno. Com isso, podemos observar que os professores têm metodologias diferentes para explicar os processos do efeito estufa e usam esses diferentes meios para chegar ao entendimento dos alunos. Observamos também que tal fenômeno é figurado como algo ruim pelos alunos e professores, apesar de ser um evento natural que favorece a proliferação da vida no planeta e as suas causas relatadas pelos alunos são basicamente as mesmas, mostrando que as causas passadas para eles durante as aulas são explicadas superficialmente.

A análise dos dados nas entrevistas indica a falta de informações dos professores, revelando lacunas na formação docente, e isso termina interferindo nitidamente na qualidade do ensino de ciências. É importante que os educadores possam participar de formações continuadas e usufruir de materiais atualizados, tanto em revistas científicas quanto na literatura especializada, possibilitando que apresentem para os seus alunos não só o conceitual, mas podendo também criar métodos para que os alunos possam visualizar esse acontecimento em experimentos, criando uma concepção adequada ao conhecimento científico.

\section{REFERÊNCIAS}

GIORDAN, A.; DE VECCHI, G. As origens do saber: das concepções dos aprendentes, aos conceitos científicos. Porto Alegre: Artes Médicas, 1996.

LIBANORE, A. C. L. S.; OBARA, A. T. Concepções alternativas sobre o efeito estufa e a formação científica de professores e alunos. In: ENCONTRO NACIONAL DA EDUCAÇÃO EM CIÊNCIAS, 7, 2009. Florianópolis, Anais... 2009.

MORTIMER, E. F. Construtivismo, mudança conceitual e ensino de ciências: para onde vamos? Investigações em Ensino de Ciências, 1996.

SILVA, A. P. F. Ensino de Ciências Naturais e as Concepções Alternativas, 2009. Web Artigos. Disponível em: <http://www.webartigos.com/artigos/ensino-de-ciencias-naturais-e-asconcepcoes-alternativas/26482/>. Acesso em 28 de abril de 2016. 